\title{
Effect of Mo-Cu cathode composition on process stability, macroparticle formation, plasma generation, and thin-film deposition in DC arc synthesis
}

Igor Zhirkov, Peter Polcik, Andrejs Petruhins, Szilard Kolozsvari and Johanna Rosén

The self-archived postprint version of this journal article is available at Linköping University Institutional Repository (DiVA):

http://urn.kb.se/resolve?urn=urn:nbn:se:liu:diva-164398

N.B.: When citing this work, cite the original publication.

Zhirkov, I., Polcik, P., Petruhins, A., Kolozsvari, S., Rosén, J., (2020), Effect of Mo-Cu cathode composition on process stability, macroparticle formation, plasma generation, and thin-film deposition in DC arc synthesis, Journal of Applied Physics, 127(1), 013301.

https://doi.org/10.1063/1.5128056

Original publication available at:

https://doi.org/10.1063/1.5128056

Copyright: AIP Publishing

http://www.aip.org/ 


\section{Effect of Mo-Cu cathode composition on process stability, macroparticle formation, plasma generation, and thin-film deposition in DC arc synthesis}

Cite as: J. Appl. Phys. 127, 013301 (2020); https://doi.org/10.1063/1.5128056

Submitted: 16 September 2019 . Accepted: 19 December 2019 . Published Online: 03 January 2020

Igor Zhirkov (D), Peter Polcik, Andrejs Petruhins, Szilard Kolozsvári (D), and Johanna Rosen
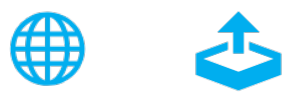

Export Citation

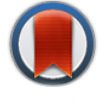

\section{ARTICLES YOU MAY BE INTERESTED IN}

Effect of helium incorporation on plasma parameters and characteristic properties of hydrogen free carbon films deposited using DC magnetron sputtering Journal of Applied Physics 127, 014901 (2020); https://doi.org/10.1063/1.5115449

Direct detection of rare earth ion distributions in gallium nitride and its influence on growth morphology

Journal of Applied Physics 127, 013102 (2020); https://doi.org/10.1063/1.5134050

Direct laser writing of graphene electrodes

Journal of Applied Physics 127, 010901 (2020); https://doi.org/10.1063/1.5120056

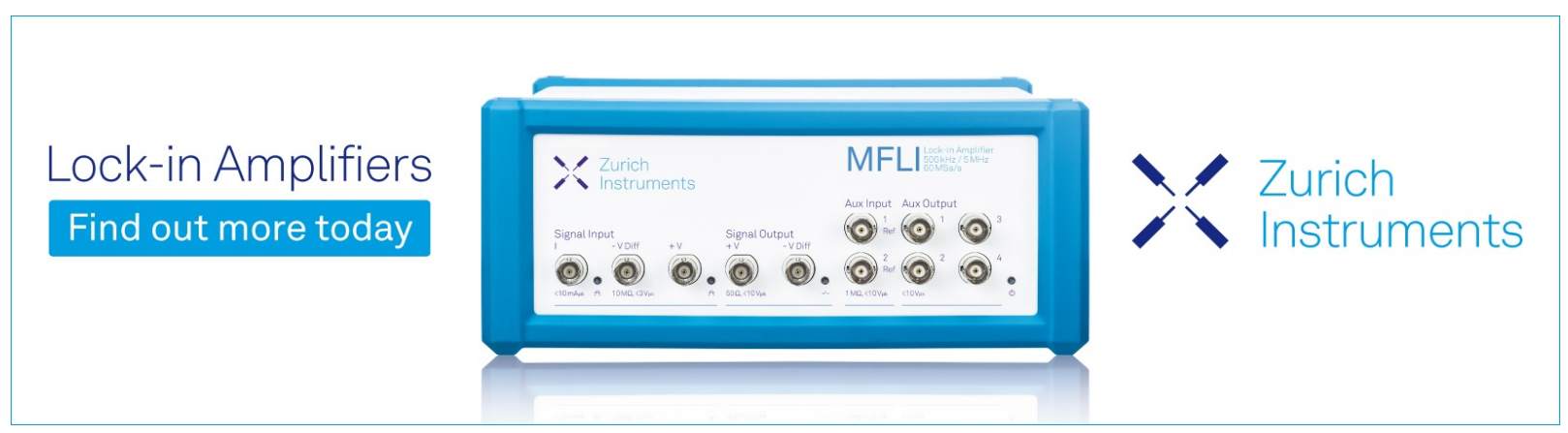




\title{
Effect of Mo-Cu cathode composition on process stability, macroparticle formation, plasma generation, and thin-film deposition in DC arc synthesis
}

Cite as: J. Appl. Phys. 127, 013301 (2020); doi: 10.1063/1.5128056

Submitted: 16 September 2019 - Accepted: 19 December 2019 .

Published Online: 3 January 2020

Igor Zhirkov, ${ }^{1, a)}$ (D) Peter Polcik, ${ }^{2}$ Andrejs Petruhins, ${ }^{1}$ Szilard Kolozsvári, ${ }^{2}$ (D) and Johanna Rosen ${ }^{1}$

\begin{abstract}
AFFILIATIONS
${ }^{1}$ Thin Film Physics Division, Department of Physics, Chemistry and Biology (IFM), Linköping University, SE-581 83 Linköping, Sweden

${ }^{2}$ PLANSEE Composite Materials GmbH, Siebenburgerstraße 23, 86983 Lechbruck am See, Germany
\end{abstract}

${ }^{a)}$ Author to whom correspondence should be addressed: igor.zhirkov@liu.se. Telephone: +46 730521012. Fax: +4613 137568.

\begin{abstract}
In this work, we present the correlation between cathode composition and features of the arcing process for $\mathrm{Mo}_{1}-{ }_{\mathrm{x}} \mathrm{Cu}_{\mathrm{x}}[\mathrm{x}=0.0,0.07(0.05)$, $0.14(0.10), 0.21(0.15), 0.40(0.3), 0.73(0.63), 0.97(0.95)$, and 1.00, atomic fraction (weight fraction)] cathodes used in a DC vacuum-arc deposition system. It is found that the stability of the arcing process crucially depends on the cathode composition. The most stable arc spot and the lowest cathode potential $(\sim 19 \mathrm{~V})$ are detected for the $\mathrm{Mo}_{0.27} \mathrm{Cu}_{0.73}$ cathode, while the $\mathrm{Mo}_{0.93} \mathrm{Cu}_{0.07}$ cathode shows the most unstable arcing process with the highest cathode potential $(\sim 28 \mathrm{~V})$. The properties of the generated plasma are also strongly dependent on the relative ratio of the cathode elements. The metal ions from the Mo and $\mathrm{Cu}$ cathodes have peak kinetic energies around $136 \mathrm{and} 62 \mathrm{eV}$, respec-

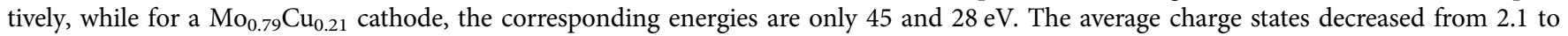
1.6 for Mo ions and from 2 to 1.2 for $\mathrm{Cu}$ ions. The intensity of macroparticle generation and the size of the droplets correlate with the relative fraction of $\mathrm{Cu}$. However, it is shown that, typically for the cathodes with a low amount of $\mathrm{Cu}$, an increased abundance of visually observed macroparticles leads to droplet-free films. The film thicknesses and their compositions also demonstrate dependencies on the elemental composition of the cathode. These results are discussed in the light of no solubility between Mo and Cu and the high temperature of the cathode surface during the arcing process.
\end{abstract}

Published under license by AIP Publishing. https://doi.org/10.1063/1.5128056

\section{INTRODUCTION}

An interesting and promising two-element material mixture is found in $\mathrm{Mo}-\mathrm{Cu}$, which combines the low thermal expansion coefficient of molybdenum with the excellent thermal/electrical conductivity of copper. ${ }^{1}$ The resulting material properties of the mixture are determined by the relative amount of $\mathrm{Cu}$ within the mix and, due to the absolute insolubility of $\mathrm{Cu}$ and Mo with each other, by how well that mix is blended. ${ }^{2,3}$ Classical mix synthesis methods, such as powder metallurgy and/or infiltration, are used for bulk material. However, these methods, being based on grains of different sizes, have limitations with respect to residual porosity and the level of intermixing of the final product.
The Mo-Cu mixture can find applications not only in a bulk form. This mixture can also be used in a thin-film form as a base-plate material for electronic microchips/systems requiring high heat dissipation rates combined with a minimal change in geometry upon heating/cooling. A widely used method for material synthesis in thin-film form is vacuum-arc evaporation, allowing the generation of metallic flux even when refractory elements are used as cathode materials. ${ }^{4-6}$ The level of elemental mixing in the generated material flux, including both ions and neutral atoms, and in the resulting films is not attainable with the classic mixing methods. There are, however, still almost no reports on arc-plasma generation from $\mathrm{Mo}-\mathrm{Cu}$ cathodes, even though arc evaporation is a common industrial 
process, and arc-deposited $\mathrm{Mo}-\mathrm{Cu}$ layers are used in the automobile industry. ${ }^{7,8}$

One previous report on the study of the vacuum-arc discharge from a Mo-Cu cathode has shown the generation of super-size (up to $0.7 \mathrm{~mm}$ ) droplets when arcing from a $\mathrm{Mo}_{0.79} \mathrm{Cu}_{0.21}$ (weight fraction) cathode. ${ }^{9}$ This observation has been explained by the discrepancy in the melting/evaporation temperatures of the two elements, with the melting temperature $(2896 \mathrm{~K})$ of Mo being higher than the evaporation temperature of $\mathrm{Cu}(2835 \mathrm{~K})$. As shown in Ref. 9, the arcing from a Mo-Cu cathode leads to the segregation of the elements at the cathode's operational surface into almost completely separate surface layers, with a Mo-rich topmost layer and a $\mathrm{Cu}$-rich layer beneath. Further arcing of these segregated layers on the cathode surface overheats the $\mathrm{Cu}$-rich layer and results, by the sudden destruction of the topmost layer, in the intensive explosionlike evaporation of $\mathrm{Cu}$ through the defect in vacuum and in the subsequent generation of super-size droplets (compared to typical sizes of up to $10 \mu \mathrm{m}) .{ }^{10}$ For more details, see Ref. 9 .

There are no reports describing the effect of $\mathrm{Mo}-\mathrm{Cu}$ cathode composition on the behavior of the arc discharge, or on the resulting plasma and/or films. However, it is expected that the significant discrepancy in the melting/evaporation temperatures should be reflected not only in the properties of the macroparticle flux but also in the intensity and properties of the remaining flux from the vacuum-arc discharge-ions and neutrals-directly involved in the film deposition processes. Therefore, a further study of arcing from a Mo-Cu cathode is highly motivated. Additionally, the diverse variations in the relative $\mathrm{Mo} / \mathrm{Cu}$ ratios of the film also motivate the investigation of a wide range of $\mathrm{Mo}-\mathrm{Cu}$ concentrations in the cathode.

Herein, we investigate plasma generation and thin-film deposition using a DC vacuum-arc source and eight different $\mathrm{Mo}-\mathrm{Cu}$ cathodes containing different relative amounts of $\mathrm{Cu}$. Investigation of the macroparticle generation is studied by visual observation of the cathode surface during operation of the arc. Such parameters of the generated plasma as its composition, ion kinetic energies, and ion charge states are studied using a mass-energy analyzer. The roughness and compositions of the cathode surfaces, the generated droplets, and the deposited films are examined using a scanning electron microscope (SEM) equipped with an energy dispersive $\mathrm{X}$-ray (EDX) spectrometer.

\section{EXPERIMENTAL DETAILS}

\section{A. Plasma analysis}

The experiments were performed using a deposition system which has an inner diameter of around $70 \mathrm{~cm}$ and is equipped with an industrial-scale DC arc source for $63 \mathrm{~mm}$ diameter cathodes, including no separate anode. Eight $[\mathrm{x}=0.0,0.07(0.05), 0.14(0.10)$, 0.21 (0.15), $0.40(0.3), 0.73(0.63), 0.97(0.95)$, and 1.00, atomic fraction (weight fraction)] cathodes with different $\mathrm{Cu}$ contents were used, as produced by powder metallurgy. The grain sizes of used $\mathrm{Cu}$ and Mo powders were $\leq 10 \mu \mathrm{m}$. The cathodes were operated for at least $15 \mathrm{~min}$ before taking any measurements, to reach the steady-state conditions. The arc current used in all experiments was $70 \mathrm{~A}$, and the base/operational pressure was around $5 \times 10^{-6}$ Torr. A mass-energy analyzer (MEA, Hiden Analytics model EQP) was placed in front of the arc source with the orifice $(50 \mu \mathrm{m}$ diameter) about $33 \mathrm{~cm}$ from the cathode surface. For each cathode, the plasma was characterized through mass-scans at fixed ion energy and energy scans at a fixed mass-to-charge ratio for all detected ions. The energy scans were recorded in steps of $0.25 \mathrm{eV} /$ charge up to $200 \mathrm{eV} /$ charge to capture the entire ion energy distribution (IED). The presence of isotopes in the ion flux and their influence on the relative ratios of the measured IEDs were evaluated in line with our previous work, see Ref. 11. Each IED was recorded at least three times to ensure the consistency of the data. Over time, the MEA orifice may become coated and the recorded intensity may be reduced as an effect of reduced orifice size. To prevent such an effect, the inlet channel was cleaned after the finalized analysis from each cathode. To determine the plasma composition, the IEDs were integrated to obtain areas proportional to the number of ions of each species. The integral average energies and charges were calculated according to Ref. 12. The average ion energies and the ratios between the total intensities of IEDs of different ions in one cathode are found to be reproducible within $5 \%$.

\section{B. Film growth, macroparticle collection, and characterization}

Films were deposited by fixing a $\mathrm{Si}(100)$ substrate in a position equivalent to the front end of the plasma analyzer, at ground potential. The deposition time was $10 \mathrm{~min}$ for all films. Temperature calibration showed a substrate temperature not exceeding $200^{\circ} \mathrm{C}$. Macroparticles were collected by placing a metallic cup at the bottom of the system. Compositions of the films and macroparticles were characterized using a LEO 1550 scanning electron microscope equipped with an energy dispersive X-ray spectrometer.

\section{Visual observation of the macroparticle generation}

Visual observation of the macroparticle generation was performed using a digital camera Nikon D800. ${ }^{13}$ Objective Nikkor 50/ 1.8 was used with aperture 8 ; sensitivity was set equal to ISO 100 . Photos were taken at a distance of $\sim 80 \mathrm{~cm}$ from the cathode surface, through a glass window.

\section{RESULTS AND DISCUSSION}

\section{A. Stability of the arcing process and the surface condition of the cathodes}

At the very beginning of the experiments, it was discovered that each of the cathodes studied herein is characterized by its own cathode voltage drop and discharge operation stability. Figure 1 demonstrates both parameters as functions of the cathode composition measured after each cathode had been operating for at least $15 \mathrm{~min}$. The discharge stability is represented as the average time ( $\geq$ ten ignitions) of uninterrupted glowing of the arc spot before its dying and reignition.

Figure 1 shows that, in the region of low $\mathrm{Cu}$ content, there is an initial reduced stability of the discharge, followed by an increased stability accompanied by a reduced discharge voltage. It should be noted that arcing from the $\mathrm{Mo}_{0.27} \mathrm{Cu}_{0.73}$ cathode has the lowest voltage drop and the spot at this cathode is able to operate 


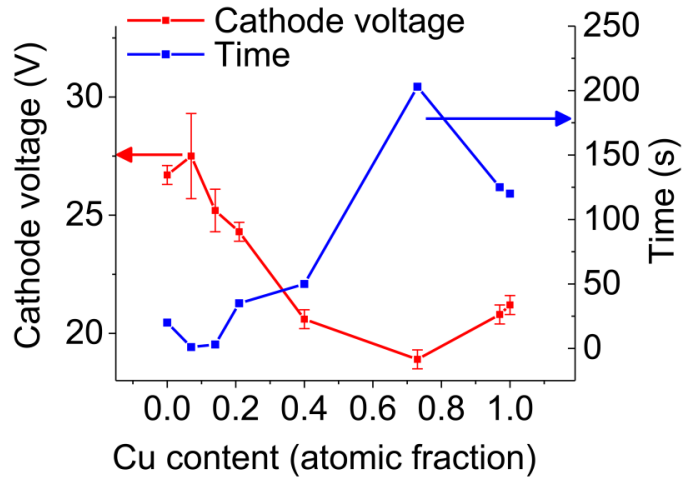

FIG. 1. Cathode voltage drop (left-hand axis) and average time of continuous operation of the discharge from an ignition (right-hand axis) as a function of $\mathrm{Cu}$ content (atomic fraction) within the cathode.

for a significantly longer time than any of the other cathodes. As generally accepted, the cathode voltage drop is in direct correlation with the cathode cohesive energy, the so-called "Cohesive Energy Rule." ${ }^{14}$ Since the cohesive energy of Mo $(6.82 \mathrm{eV})$ is significantly higher than that of $\mathrm{Cu}(3.49 \mathrm{eV})$, a higher cathode drop for the Mo cathode can be expected. However, because $\mathrm{Mo}$ and $\mathrm{Cu}$ are not able to form any intermetallic compounds, it may not be appropriate to use the cohesive energy rule to explain the extremum at $x=0.73$ seen in Fig. 1. Still, it should be noted that for the $\mathrm{Mo}_{0.27} \mathrm{Cu}_{0.73}$ cathode, the calculation performed in line with Ref. 9 on the energies required for the melting and/or evaporation of Mo and $\mathrm{Cu}$ show that the energy needed to melt $37 \mathrm{~kg}$ of Mo coincides with the energy required for melting $63 \mathrm{~kg}$ of $\mathrm{Cu}$.
With the aim of clarifying the processes accompanying the glowing of the arc, the operating surfaces of the cathodes were studied via visual observation during the arcing process, with the following photographic and SEM characterization. Figure 2 presents the collected images.

As can be seen by comparison of Figs. 1 and 2, the stability of the discharge is likely to be correlated with the cathode surface condition. Despite the fact that the surfaces of all the cathodes studied herein as-received (not shown here) were equally smooth before the operation, after just $\sim 15 \mathrm{~min}$ of arcing, the surfaces become very different. The most pronounced change and the roughest surface, which can be observed even with the naked eye (Fig. 2, middle row), are found for the $\mathrm{Mo}_{0.93} \mathrm{Cu}_{0.07}$ cathode; there the arc seems unable to glow at all. The surface of the $\mathrm{Mo}_{0.86} \mathrm{Cu}_{0.14}$ cathode, which is also characterized by a very unstable arc, is also found to be quite rough, with inconsistent craters, sharp crater edges, and empty spaces (voids) under solidified crater splashes. The surfaces of the other cathodes are much smoother. As a result, it can be assumed that the instability is caused by the presence of places where the arc spot loses a direct view of the system anode and where plasma from the spot can be hampered by solidified cathode material from previous operation cycles, on a potentially very rough surface. The greatest voltage drop, which is for the $\mathrm{Mo}_{0.93} \mathrm{Cu}_{0.07}$ cathode, see Fig. 1, is evidently correlated with the complex geometry of the corresponding surface and the hampered glowing of the discharge.

The bulk porosity of the cathode may also influence the discharge characteristics. For the herein investigated cathodes, two microstructure types can be expected, as explained by the insolubility of $\mathrm{Mo}$ and $\mathrm{Cu}$ and the significant discrepancy between their melting temperatures. For the cathodes with low $\mathrm{Cu}$ content, there is a Mo skeleton with the space between the grains only partially filled with $\mathrm{Cu}$. These cathodes are expected to have the largest

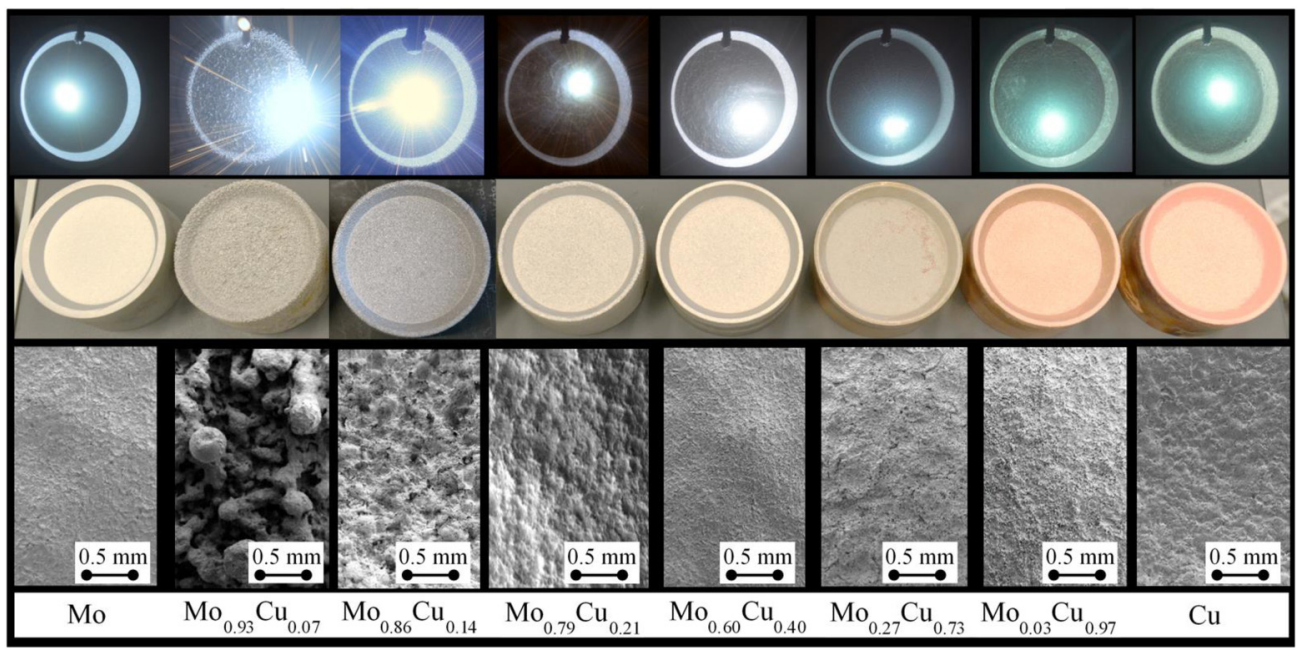

FIG. 2. Visual observation of arcing of the studied cathodes (topmost row), their photographs after operation for $\sim 15$ min (middle row), and the corresponding SEM images (bottom row). All photographs were taken with the same exposure times and ISOs. 
deviation from the theoretical density and the highest residual porosity. The cathodes with high $\mathrm{Cu}$ content, on the other hand, consist of a continuous $\mathrm{Cu}$ matrix with isolated Mo grains embedded in the matrix. The cathode density can, therefore, be expected to be closer to the theoretical value. A variable porosity of the cathodes is evident from our evaluation of the cathode density based on Archimedes' principle, and the measured discrepancy between the cathode weights measured in air and in water. Figure 3 shows the resulting bulk densities of the cathodes as a fraction of the corresponding theoretical densities for respective $\mathrm{Mo}-\mathrm{Cu}$ compositions. The unstable $\mathrm{Mo}_{0.93} \mathrm{Cu}_{0.07}$ and $\mathrm{Mo}_{0.86} \mathrm{Cu}_{0.14}$ cathodes have a significantly higher residual porosity compared to the other cathodes. The correlation between the discharge characteristics (Fig. 2) and the bulk densities of the cathodes (Fig. 3) clearly indicates that the residual porosity of the cathode can play a role in the arcing process. This may be explained by the porosity influencing the surface smoothness and/or determining the level of elemental distribution (from, e.g., segregation) within the cathode.

The smoothness of the cathode surface can also be significantly changed by the arc discharge. As previously reported for a $\mathrm{Mo}_{0.79} \mathrm{Cu}_{0.21}$ cathode, the insolubility of the elements and a significant discrepancy in their melting temperatures result in the segregation of the elements near the operating cathode surface. ${ }^{9}$ However, in the $\mathrm{Mo}_{0.93} \mathrm{Cu}_{0.07}$ and $\mathrm{Mo}_{0.86} \mathrm{Cu}_{0.14}$ cathodes, where the amount of $\mathrm{Cu}$ is lower, it looks as though all $\mathrm{Cu}$ within the liquid bath of the spot and in its vicinity is disappearing during spot operation. Intensive evaporation of $\mathrm{Cu}$ may continue during solidification of that bath. This additionally cools down the previously operated crater and accelerates the process of its solidification. A quicker cathode solidification may explain the sharper edges of the craters of the cathodes with lower $\mathrm{Cu}$ content, while intensive removal of $\mathrm{Cu}$ explains the presence of voids on their operational surfaces. For the $\mathrm{Mo}_{0.93} \mathrm{Cu}_{0.07}$ cathode, the applied power (see the cathode voltage drop in Fig. 1) is the highest. The highest drop in the cathode potential can lead to an even higher local temperature of the surface. As a result, the vapor pressure of the overheated $\mathrm{Cu}$ within and around the spot is also higher. It is suggested that the correspondingly high pressure of overheated $\mathrm{Cu}$ inclusions within

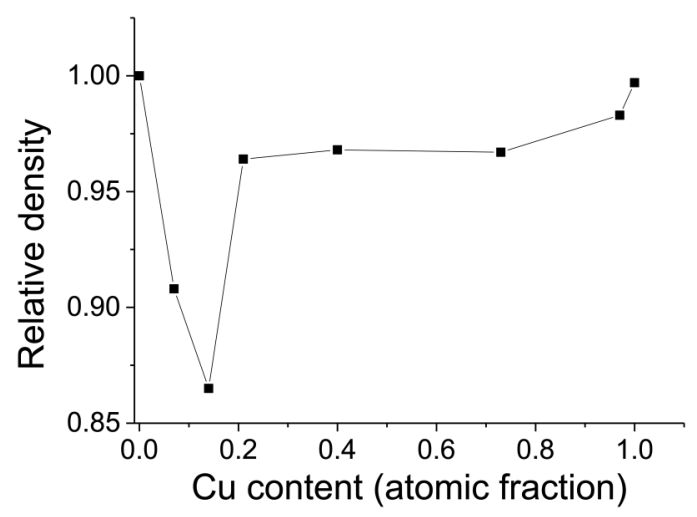

FIG. 3. The evaluated cathode (bulk) density as a function of $\mathrm{Cu}$ content, expressed as a fraction of the corresponding theoretical density. the solidifying cathode material is responsible for the observed most intensive increase in the roughness of the operating surface of the $\mathrm{Mo}_{0.93} \mathrm{Cu}_{0.07}$ cathode. However, for more details on the processes occurring, additional experimental work is required.

\section{B. Generation of the macroparticle flux}

The cathodes for which the discharge is unstable provide a relatively intensive flux of large droplets, see the bright traces in the topmost row of Fig. 2. In our previous work, while investigating the features of the discharge from a $\mathrm{Mo}_{0.79} \mathrm{Cu}_{0.21}$ cathode, ${ }^{9}$ the generation of super-size macroparticles has been detected. A mechanism for macroparticle generation based on the discrepancy in melting/ evaporation temperatures of $\mathrm{Mo}$ and $\mathrm{Cu}$ and the observed segregation of the elements into almost completely separate surface layers has been suggested in that work. It was assumed that the molten Mo-rich surface layer, upon a sudden surface deformation associated with the explosive nature of the arc spots, can lead to instantaneous explosive vaporization of $\mathrm{Cu}$, resulting in the formation of Mo-rich super-size macroparticles (with diameters of up to 0.7 $\mathrm{mm}$ ), for more details, see Ref. 9.

In the present work, super-size droplet generation has been confirmed for the $\mathrm{Mo}_{0.79} \mathrm{Cu}_{0.21}$ cathode. However, even higher intensities of the droplet flux have been visually observed for the $\mathrm{Mo}_{0.93} \mathrm{Cu}_{0.07}$ and $\mathrm{Mo}_{0.86} \mathrm{Cu}_{0.14}$ cathodes. The rough surfaces of those cathodes and the limited amount of $\mathrm{Cu}$ suggest that the generation of droplets from the spots may occur in a similar way as the proposed mechanism for a W-C cathode, see Ref. 5. This mechanism is based on the electrical explosion of thin necks attaching the cathode surface with protrusions. The rough surfaces of the $\mathrm{Mo}_{0.93} \mathrm{Cu}_{0.07}$ and $\mathrm{Mo}_{0.86} \mathrm{Cu}_{0.14}$ cathodes allow the presence of a significant number of such necks, which are prone to explosion during the discharge. The demonstrated high residual porosity of those cathodes (Fig. 3) could also promote such neck formation and influence the mechanism of droplet generation.

An important observation concerning the macroparticle formation has been made for the $\mathrm{Mo}_{0.93} \mathrm{Cu}_{0.07}$ cathode. It has been found that some of the surface protrusions on this cathode have a smooth balloonlike form, see Fig. 4(a). The same form has been found for droplets collected from the bottom of the system, see Fig. 4(b). The collected droplets were found to be up to $0.5 \mathrm{~mm}$ in diameter, but were fragile and had a hollow core, see Fig. 4(c). This suggests that they were pumped up and formed by overheated $\mathrm{Cu}$ vapor formed from a $\mathrm{Cu}$ inclusion surrounded by a molten Mo bath. Droplet acceleration, in this case, can occur through the electrical explosion of the neck, i.e., the thin connection between the droplet and the cathode surface. However, an acceleration based on the reactive movement of a droplet due to the sudden destruction of its surface and outflowing of the overheated $\mathrm{Cu}$ vapor is also possible. The creation of such balloonlike droplets within the arc spot has not been reported before, and a further study of this may not only improve our understanding of the discharge in general but also allow the identification of new areas of application.

\section{Plasma properties}

The arcing process from the $\mathrm{Mo}_{0.93} \mathrm{Cu}_{0.07}$ and $\mathrm{Mo}_{0.86} \mathrm{Cu}_{0.14}$ cathodes is very unstable and did not allow continuous repeatable 


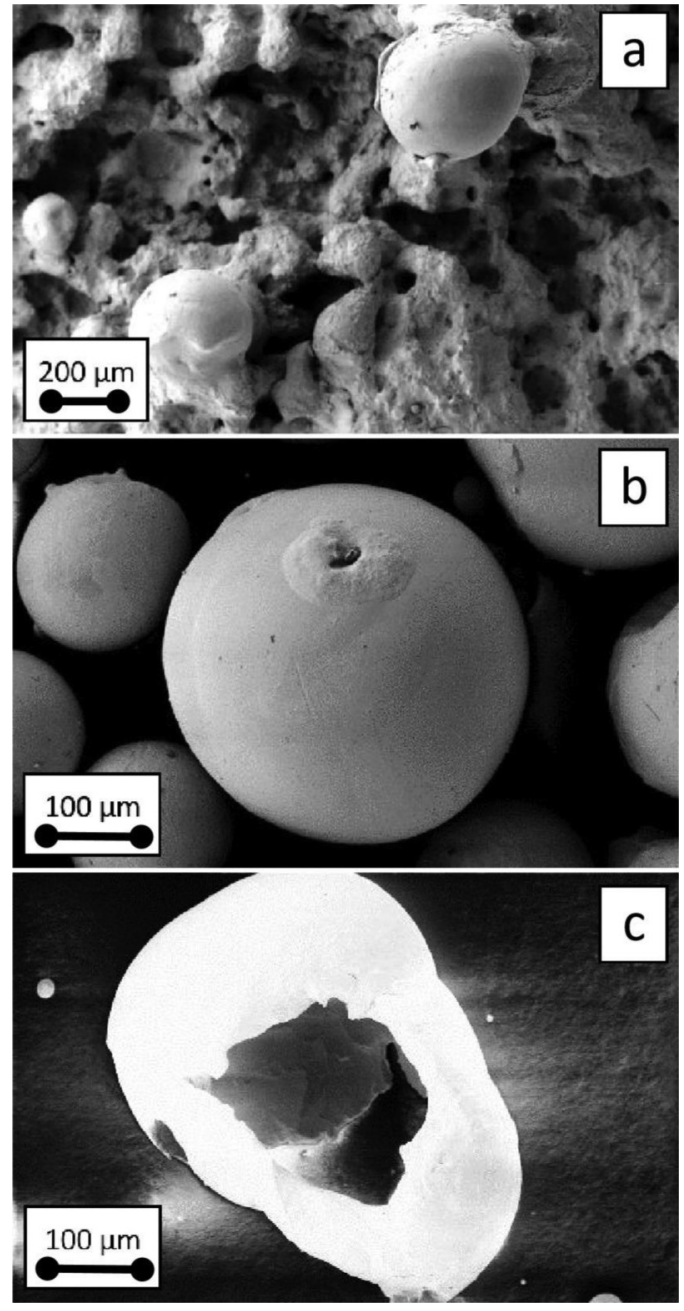

FIG. 4. SEM image of the operated surface of the $\mathrm{Mo}_{0.93} \mathrm{Cu}_{0.07}$ cathode (a), SEM image of one of the collected macroparticles from the bottom of the system (b), and SEM image of one of the collected and later broken droplets, demonstrating a hollow core (c).

plasma diagnostics, while plasma from all the other cathodes was studied in detail. Mo and $\mathrm{Cu}$ ions of charge states up to 5+ and 4+, respectively, were detected in plasma from pure $\mathrm{Mo}$ and $\mathrm{Cu}$ cathodes. For the complex Mo-Cu cathodes, the ion charges of both elements were detected up to $3+$. Figure 5 presents measured ion energy distribution functions for two elemental $\mathrm{Mo}$ and $\mathrm{Cu}$ cathodes and four Mo-Cu cathodes of different compositions.

Figure 5 demonstrates the effect of mixing $\mathrm{Mo}$ and $\mathrm{Cu}$ in one cathode. It can clearly be seen that, for plasma from the composite cathodes, the peak kinetic energies of the ions are significantly reduced compared to the plasma generated from the elemental cathodes, to about $50 \%$. In order to generate a clearer representation of the effect, such plasma properties as average ion energy, average ion charge state, plasma composition, and total plasma
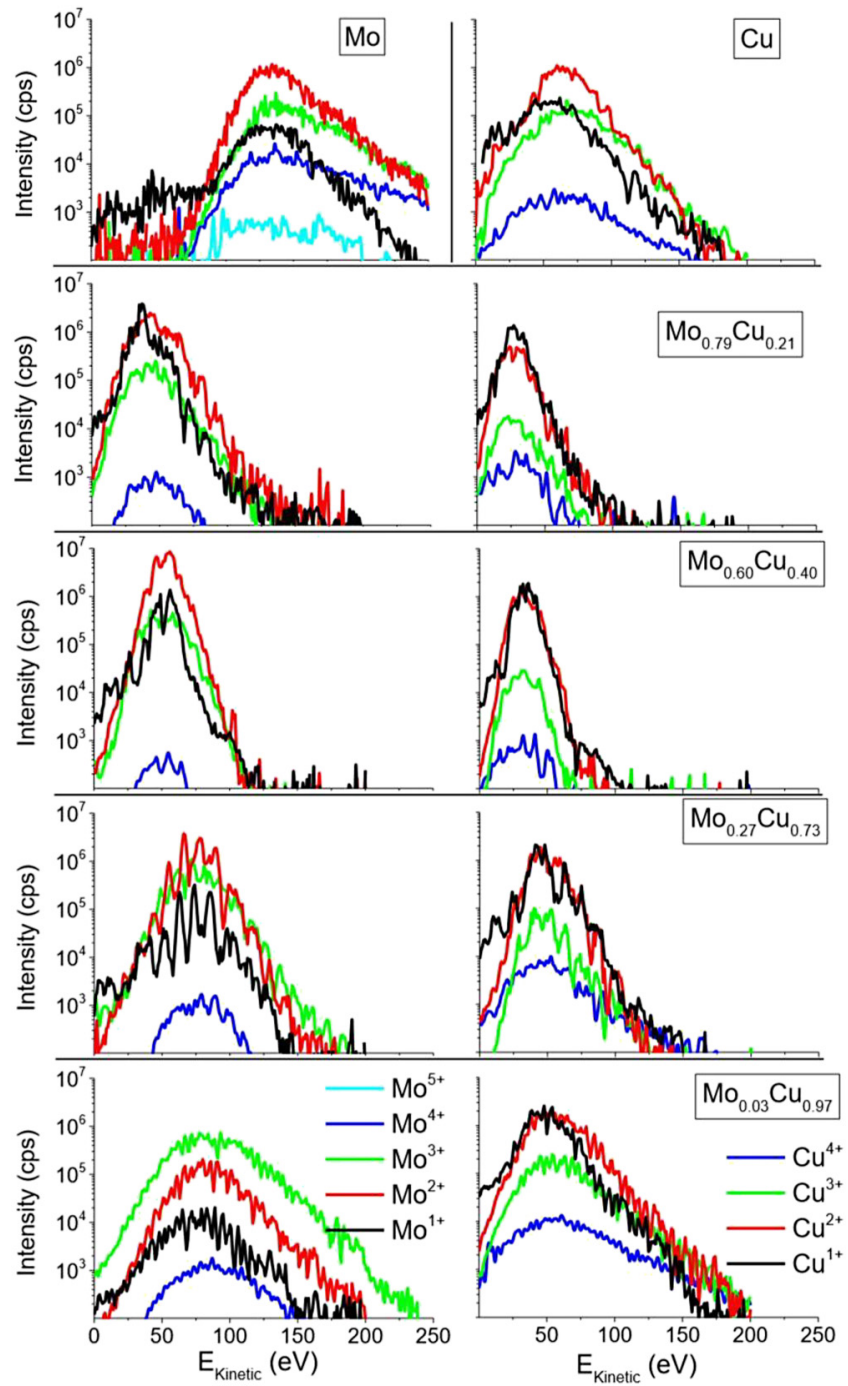

FIG. 5. lon energy distribution (IED) functions measured from plasma generated from the two elemental cathodes (the topmost row) and four Mo-Cu cathodes of different compositions (remaining four rows).

intensity have been estimated for plasma from each of the cathodes through the corresponding IEDs, see Fig. 6.

It is well known that, for cathodic arc, the kinetic energies of ions, their charge states, and even the cathode voltage drop are all correlated with the cohesive energy of the cathode material. ${ }^{6}$ It was empirically established that all of these characteristics are higher for plasma from an element which has a higher cohesive energy. The properties of plasma from the herein evaluated cathodes suggest that the cohesive energy of the Mo-Cu mixture is lower than those for both the pure Mo $(6.82 \mathrm{eV})$ and $\mathrm{Cu}(3.49 \mathrm{eV})$ elements. This can be explained, at least in part, by an improved intermixing of the elements at the cathode operational surface during arcing, while 

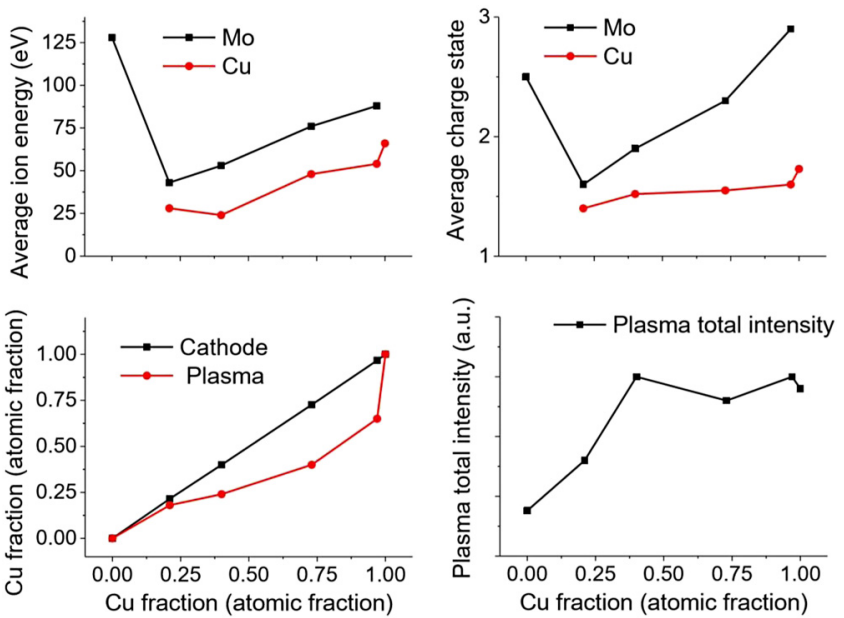

FIG. 6. Average ion energy (top left), average ion charge (top right), relative amount of $\mathrm{Cu}$ within the generated plasma (bottom left), and total intensity of all collected ions (bottom right) as functions of $\mathrm{Cu}$ content (atomic fraction) within the cathodes. The bottom left graph also shows the $\mathrm{Cu}$ content within the cathodes (black line)

the absence of intermetallic bonds between $\mathrm{Mo}$ and $\mathrm{Cu}$ suggests a reduction in the cohesive energy, i.e., the energy required to remove $\mathrm{Cu}$ (or $\mathrm{Mo}$ ) from a surrounding of $\mathrm{Mo}$ (or $\mathrm{Cu}$ ). However, this is a rough assumption based on the corresponding reduction in the plasma/discharge properties. To clarify the assumption, an evaluation of the cohesive energy of the $\mathrm{Mo}-\mathrm{Cu}$ mixtures is required; however, this is beyond the scope of the present study.

An additional mechanism for the reduction of energy and charge, based on the intensive vaporization of $\mathrm{Cu}$ considered above, may also be possible. The vapor pressure of $\mathrm{Cu}$ at the melting temperature of Mo $(2896 \mathrm{~K})$ is around $1 \mathrm{~atm}\left(10^{5} \mathrm{~Pa}\right)$. A rough estimation of the maximum density of $\mathrm{Cu}$ vapor can be made by using the ideal gas equation $P=N \cdot k \cdot T$ at the Mo melting temperature. The calculated density is $\sim 2.5 \times 10^{24}$; this density is the maximum and is expected to reduce with the plasma expansion. However, comparing this density with plasma densities estimated through the Saha freezing model $(\mathrm{Cu}$ cathode $\sim 2.3 \times 10^{24}$; and Mo cathode $\left.\sim 6 \times 10^{24}\right)$, ${ }^{6}$ it is possible to assume that the arc from the Mo-Cu cathodes studied herein glows in a relatively dense cloud of $\mathrm{Cu}$ vapor. One can assume that the $\mathrm{Cu}$ vapor mainly influences the generated ion flux through ion-neutral collisions and, therefore, the reduction in the ion kinetic energies for the Mo-Cu cathodes detected herein could possibly be explained through a loss of kinetic energy from collisions with neutral particles. However, as it is well known, the peak velocities of all ions generated from composite cathodes are the same-see the "Velocity rule." ${ }^{15}$ Herein, the detected $\mathrm{Mo}$ and $\mathrm{Cu}$ ions from, for instance, the $\mathrm{Mo}_{0.79} \mathrm{Cu}_{0.21}$ cathode have peak kinetic energies equal to $45 \mathrm{eV}$ and $28 \mathrm{eV}$, respectively; this corresponds to the ion velocities of $9.5 \mathrm{~km} / \mathrm{s}$ and $9.2 \mathrm{~km} / \mathrm{s}$, which is consistent with the velocity rule. Furthermore, it is known that the velocity of a heavier ion (Mo) is less affected in the same environment compared with that of a lighter ion $(\mathrm{Cu}) .{ }^{16,17}$ So, the matching of velocities shows that most of the $\mathrm{Mo}$ and $\mathrm{Cu}$ ions were only exposed to the acceleration mechanisms in the spot, and that collisions within the vapor do not play a significant role, at least not for the kinetic energies.

It is known that metallic vapor can serve as an insulator, and the intensive generation of neutrals from the spot may be one of the reasons for the extinction of this spot and the birth of a new one. For the suggested case of the present work, initiation of the spot occurs in already dense metallic vapors, which can affect the operation of the arc. The explosive nature of the arc discharge implies explosive electron emission. Along the lines of the recently suggested "Traveling Hump" theory, ${ }^{18}$ which combines the hump and gasdynamic theories ${ }^{19}$ with the ecton model $^{20}$ of operation of the arc spot, the emitted electrons move faster than the ions and are thus situated at the boundary of the expanding plasma. This electron front extends into the chamber and along its path it can collide with and ionize any neutral atoms encountered. An increase in the number of such collisions will reduce the initial energy of the electrons (cool them down) and, as a result, reduce the velocity of the front of the expanding plasma. Theories describing the expansion of plasma in a vacuum (including the "Traveling Hump" theory) establish a direct correlation between the energy (velocity) of the expanding electron cloud and the resulting kinetic energy of the accelerated ions. ${ }^{21-23}$ Additionally, the ions created from the vapor can also be involved in the acceleration process. If so, then, while the number and total weight of the ions involved in the acceleration process will increase, the number of fast electrons causing ion acceleration will not change, and this will lead to a decrease in the acceleration of the whole plasma. Hence, the suggested intensive vaporization of $\mathrm{Cu}$ in the $\mathrm{Mo}-\mathrm{Cu}$ cathode can lead to a reduction in the ion kinetic energies and, at the same time, maintain the "velocity rule" condition.

The $\mathrm{Cu}$ content (considering ions only) in the plasma from all Mo-Cu cathodes is lower than that in the corresponding cathodes, see Fig. 6. An explanation can be found in the trapping of $\mathrm{Cu}$ under the topmost Mo-rich layer discovered for the $\mathrm{Mo}_{0.79} \mathrm{Cu}_{0.21}$ cathode, ${ }^{9}$ and also detected at the surfaces of all the other cathodes (Fig. 2). In this case, the arc spot, which runs through the Mo-rich surfaces, leads to preferential ionization of Mo, with ionization of $\mathrm{Cu}$ only when the spot reaches an exposed $\mathrm{Cu}$ area. Due to the fact that, in the steady-state regime of the discharge, the composition of the total material flux (ions, neutrals, and droplets) from a cathode has to be the same as that of the cathode, the lack of $\mathrm{Cu}$ within the plasmas suggests that a significant part of the $\mathrm{Cu}$ flux is generated as neutral vapor, which is consistent with the glowing of the spot in an environment of a relatively dense cloud of $\mathrm{Cu}$ neutrals assumed above.

\section{Analysis of the deposited films}

Films were deposited from all "stable" cathodes, for a duration of $10 \mathrm{~min}$ each. Figure 7 demonstrates SEM diagnostics of the film surfaces. The difference between the numbers of macroparticles detectable on the film surfaces deposited from the elemental Mo and $\mathrm{Cu}$ cathodes can be explained by the dependence of the intensity of generation of macroparticles on the melting temperatures of the cathodes. It is known that, for a cathodic element with a higher melting temperature (Mo), the number and size of macroparticles 

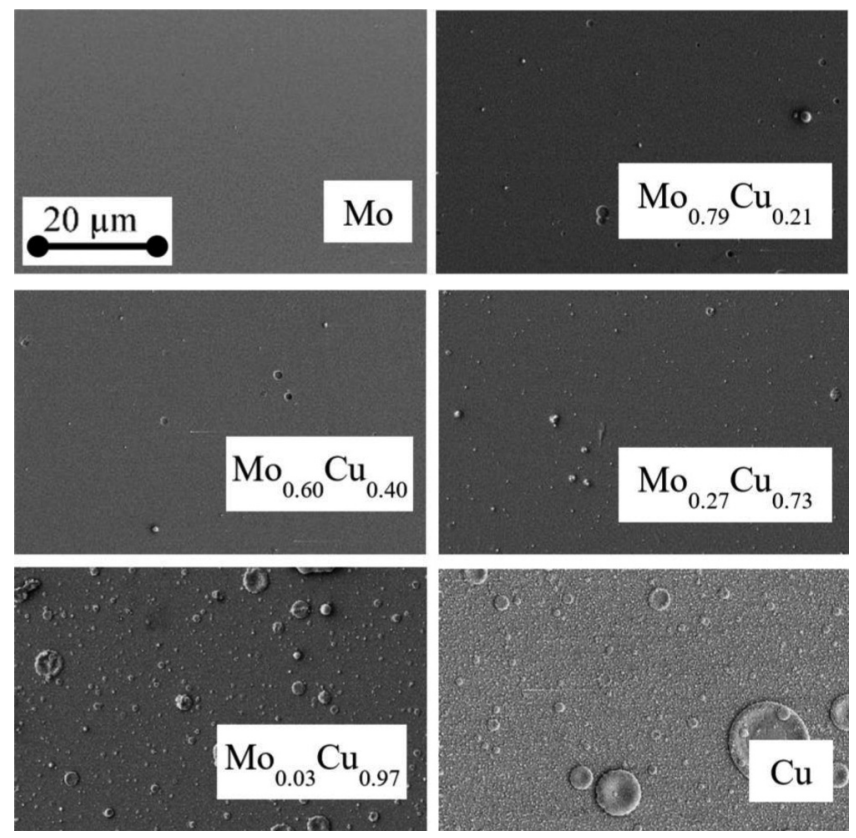

FIG. 7. SEM images of the surfaces of the films deposited from cathodes of different compositions (the label corresponds to cathode notation).

are less than those for an element which has a lower melting temperature $(\mathrm{Cu}) .{ }^{10,24}$ Though, due to the possible reflection of macroparticles from the film/substrate, it is not possible to establish a clear correlation. However, it is clear that the film generated from the $\mathrm{Cu}$ cathode seems to have a greater roughness than the film generated from the Mo cathode.

The different degrees of roughness of the films deposited from the composite cathodes (Fig. 7) cannot be explained by the difference in their melting points, as the phase diagram of Mo-Cu does not show any discrepancy between the melting temperatures of the compositions in the present study. ${ }^{25}$ At the same time, the roughness of the films seems to increase significantly with a cathode $\mathrm{Cu}$ content of 73 at. \% and higher. An explanation can be found in the formation of the Mo-rich layer on the cathode operating surface, as shown in Ref. 9 and discussed above. It is suggested that an increase in the melting temperature of the cathode surface formed causes a reduced intensity in the droplet generation process. Additionally, the droplets consisting of the material with a high melting temperature will bounce more easily from the film's surface due to a faster solidification. This is consistent with the observation that all droplets on the film surfaces from the cathodes with a $\mathrm{Cu}$ atomic fraction lower than 0.73 are found to have a higher Mo content than in the corresponding cathode. For the $\mathrm{Mo}_{0.27} \mathrm{Cu}_{0.73}$ cathode, some droplets of pure $\mathrm{Cu}$ can be detected, and their number increases for the $\mathrm{Mo}_{0.03} \mathrm{Cu}_{0.97}$ cathode. This clearly shows that there are some $\mathrm{Cu}$ regions existing on those cathode surfaces and that the relative area of those regions increases with the $\mathrm{Cu}$ content.

It must be also noted that the intensive flux of visible droplets from the $\mathrm{Mo}_{0.79} \mathrm{Cu}_{0.21}$ cathode is not reflected in the roughness of the corresponding film. As expected, the "huge" droplets from that cathode are too big to attach to the film; see the details in Ref. 9.

Figure 8 shows the results of EDX diagnostics of the deposited films and the corresponding film thickness. As can be seen, the film compositions are generally coincide with the cathode compositions and the film thickness generally follows the change in the plasma intensity (see Fig. 6).

The consistent composition when comparing the films with the cathodes and the reduced $\mathrm{Cu}$ content in the ionized phase of the plasmas from the Mo-Cu cathodes (see Fig. 6) show that a perceptible amount of $\mathrm{Cu}$ arrives at the films in the neutral phase as neutral vapor, as suggested and discussed above. With the melting temperature of Mo $(2896 \mathrm{~K})$ being higher than the evaporation temperature of $\mathrm{Cu}(2835 \mathrm{~K})$, and with an expected higher temperature of the arc spot on a Mo surface compared to that on a $\mathrm{Cu}$ surface, the higher vaporization of $\mathrm{Cu}$ compared to that of Mo in a Mo-Cu cathode is not surprising. Still, a more detailed explanation is nontrivial, considering the nonhomogeneous surface state with the $\mathrm{Mo}$ - and $\mathrm{Cu}$-rich regions, and a change in the total material flux (evident through a change in film deposition rate) and ion energies with a change in the cathode composition. The greater than expected amount of $\mathrm{Cu}$ within the film from the $\mathrm{Mo}_{0.79} \mathrm{Cu}_{0.21}$ cathode seems to be caused by the fact that visible droplets from that cathode are almost pure Mo, although they are not adhering to the film's surface.

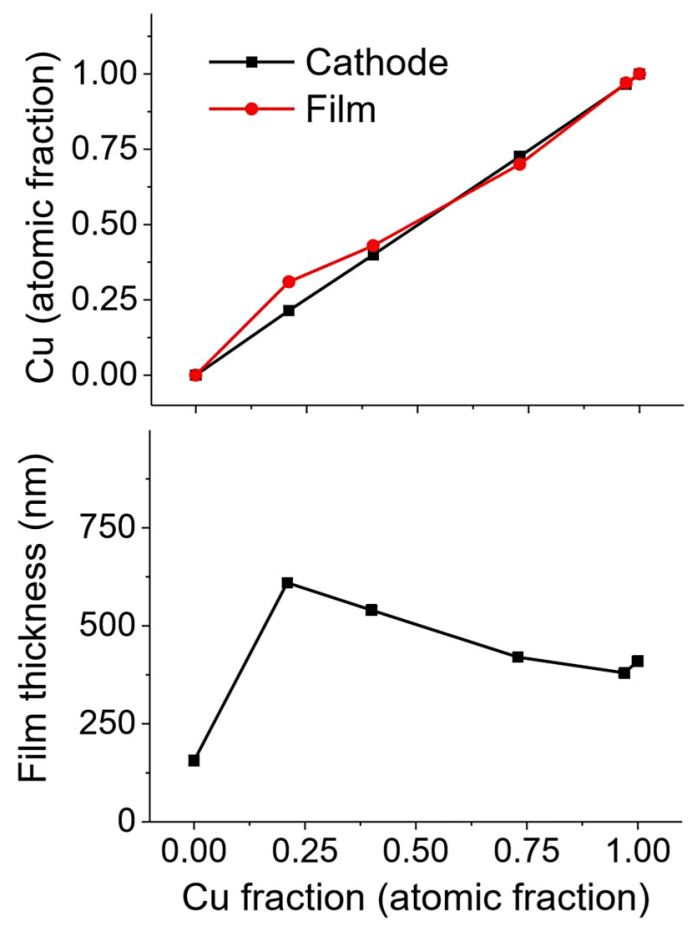

FIG. 8. A relative amount of $\mathrm{Cu}$ within the deposited films (top) and film thickness (bottom) as functions of $\mathrm{Cu}$ content (atomic fraction) within the cathodes. The top graph also shows the $\mathrm{Cu}$ content within the cathodes (black line). 


\section{CONCLUSION}

In the present work, we have studied the characteristics of an arc discharge from the $\mathrm{Mo}, \mathrm{Mo}_{0.93} \mathrm{Cu}_{0.07}, \mathrm{Mo}_{0.86} \mathrm{Cu}_{0.14}$, $\mathrm{Mo}_{0.79} \mathrm{Cu}_{0.21}, \mathrm{Mo}_{0.60} \mathrm{Cu}_{0.40}, \mathrm{Mo}_{0.27} \mathrm{Cu}_{0.73}, \mathrm{Mo}_{0.03} \mathrm{Cu}_{0.97}$, and $\mathrm{Cu}$ cathodes (the cathode notation given as atomic fraction). A dependence of the arc potential (19-28 V) on the cathode composition is shown, with a rough cathode surface being formed and a somewhat unstable arc process for a $\mathrm{Cu}$ content lower than or equal to an atomic fraction of 0.14 . An intensive flux of very large (up to $0.5 \mathrm{~mm}-0.7 \mathrm{~mm}$ ) and glowing macroparticles from the $\mathrm{Mo}_{0.93} \mathrm{Cu}_{0.07}, \mathrm{Mo}_{0.86} \mathrm{Cu}_{0.14}$, and $\mathrm{Mo}_{0.79} \mathrm{Cu}_{0.21}$ cathodes has also been observed, although a bounce-off effect can be concluded from the lack of corresponding particles on the film surface. Furthermore, we have characterized plasma and deposited films from the Mo, $\mathrm{Mo}_{0.79} \mathrm{Cu}_{0.21}, \mathrm{Mo}_{0.60} \mathrm{Cu}_{0.40}, \mathrm{Mo}_{0.27} \mathrm{Cu}_{0.73}, \mathrm{Mo}_{0.03} \mathrm{Cu}_{0.97}$, and Cu cathodes. A significant reduction in the ion energies was demonstrated for all $\mathrm{Mo}-\mathrm{Cu}$ cathodes (compared to the single-element cathodes). This may be explained by the arc spot operating in a relatively high density of $\mathrm{Cu}$ vapor caused by intensive vaporization of the $\mathrm{Cu}$ cathode content. Despite an observed discrepancy between the composition of the cathode and the plasma, the resulting compositions of the deposited films are found to be consistent with the corresponding cathode compositions.

\section{ACKNOWLEDGMENTS}

We acknowledge the support from the Knut and Alice Wallenberg (KAW) Foundation for a Fellowship Grant and Project funding (No. KAW 2015.0043) and from the Swedish Government Strategic Research Area in Materials Science on Functional Materials at Linköping University (Faculty Grant SFO-Mat-LiU No. 2009 00971). The Swedish Research Council is also gratefully acknowledged through Project No. 642-2013-8020.

\section{REFERENCES}

${ }^{1}$ G. Jiang, L. Diao, and K. Kuang, "Properties of $\mathrm{WCu}, \mathrm{MoCu}$, and $\mathrm{Cu} / \mathrm{MoCu} /$ $\mathrm{Cu}$ high-performance heat sink materials and manufacturing technologies," in Advanced Thermal Management Materials (Springer, New York, 2013), pp. 73-87.

${ }^{2}$ G. Chen, G. Wu, D. Zhu and Q. Zhang, "The thermo-physical properties of high dense $\mathrm{Mo} / \mathrm{Cu}$ composites fabricated by squeeze casting technology," in Electronic Packaging Technology, 2005 6th International Conference on (IEEE) (IEEE, 2005), pp. 321-324.

${ }^{3}$ P. Subramanian and D. Laughlin, "The Cu-Mo (copper-molybdenum) system," Bull. Alloy Phase Diagrams 11(2), 169-172 (1990).

${ }^{4}$ I. Zhirkov, A. Petruhins, L. Näslund, S. Kolozsvári, P. Polcik, and J. Rosén, "Vacuum arc plasma generation and thin film deposition from a $\mathrm{TiB}_{2}$ cathode," Appl. Phys. Lett. 107(18,), 184103 (2015).

5. Zhirkov, P. Polcik, S. Kolozsvari, and J. Rosen, "Macroparticle generation in DC arc discharge from a WC cathode," J. Appl. Phys. 121(10), 103305 (2017).
${ }^{6}$ A. Anders, Cathodic Arcs: From Fractal Spots to Energetic Condensation, 1st ed. (Springer, New York, 2008).

${ }^{7}$ F. Seibert, M. Döbeli, D. Fopp-Spori, K. Glaentz, H. Rudigier, N. Schwarzer, B. Widrig, and J. Ramm, "Comparison of arc evaporated Mo-based coatings versus $\mathrm{Cr} 1 \mathrm{~N} 1$ and $\mathrm{Ta}-\mathrm{C}$ coatings by reciprocating wear test," Wear 298-299, 14-22 (2013).

${ }^{8}$ M. Ürgen, A. Çakır and A. Erdemir, "Advanced tribological coatings for automotive applications," in International Conference on Automotive Technology, Istanbul, Turkey (Istanbul Technical University, 2004).

${ }^{9}$ I. Zhirkov, A. Petruhins, P. Polcik, S. Kolozsvári, and J. Rosen, "Generation of super-size macroparticles in a direct current vacuum arc discharge from a Mo-Cu cathode," Appl. Phys. Lett. 108, 054103 (2016).

${ }^{10}$ S. Anders, A. Anders, K. Man Yu, X. Yao, and I. Brown, "On the macroparticle flux from vacuum arc cathode spots," IEEE Trans. Plasma Sci. 21(5), 440 (1993).

${ }^{11}$ I. Zhirkov, E. Oks, and J. Rosen, "Experimentally established correlation between ion charge state distributions and kinetic ion energy distributions in a direct current vacuum arc discharge," J. Appl. Phys. 117(9), 093301 (2015).

${ }^{12}$ I. Zhirkov, A. Eriksson, A. Petruhins, M. Dahlqvist, A. Ingason, and J. Rosen, "Effect of Ti-Al cathode composition on plasma generation and plasma transport in direct current vacuum arc," J. Appl. Phys. 115, 123301 (2014).

${ }^{13}$ See http://imaging.nikon.com/lineup/dslr/d800/index.htm for "Imaging Products," Nikon Corporation, 2012.

${ }^{14}$ A. Anders, "Correlation between cathode properties, burning voltage, and plasma parameters of vacuum arcs,” J. Appl. Phys. 89, 7764 (2001).

${ }^{15}$ I. Zhirkov, A. Eriksson, and J. Rosen, "Ion velocities in direct current arc plasma generated from compound cathodes," J. Appl. Phys. 114, 213302 (2013).

${ }^{16}$ I. Beilis, A. Shashurin, and R. Boxman, "Measurement of ion flux as a function of background gas pressure in a hot refractory anode vacuum arc," IEEE Trans. Plasma Sci. 35(4), 973-979 (2007).

${ }^{17}$ I. Zhirkov, E. Oks, and J. Rosen, "Effect of $\mathrm{N}_{2}$ and Ar gas on DC arc plasma generation and film composition from Ti-Al compound cathodes," J. Appl. Phys. 117, 213301 (2015)

${ }^{18} \mathrm{~A}$. Anders, "Ion energies in vacuum arcs: A critical review of data and theories leading to traveling potential humps," in Proceedings - International Symposium on Discharges and Electrical Insulation in Vacuum, ISDEIV (IEEE, 2014), pp. 201-204.

${ }^{19}$ B. Jüttner, V. Puchkarev, E. Hantzsche, and I. Beilis, "Cathode spots," in Handbook of Vacuum Arc Science and Technology Fundamentals and Applications (Noyes, NJ, 1995), pp. 73-281.

${ }^{20} \mathrm{G}$. Mesyats, "Ecton mechanisms of the vacuum arc cathode spot," IEEE Trans. Plasma Sci. 23(6), 879-883 (1995).

${ }^{21}$ P. Mora, "Plasma expansion into a vacuum," Phys. Rev. Lett. 90, 185002 (2003).

${ }^{\mathbf{2 2}}$ J. Crow, P. Auer, and J. Allen, "The expansion of a plasma into a vacuum," J. Plasma Phys. 14, 65-76 (1975).

${ }^{23}$ C. Sack and H. Schamel, "Evolution of a plasma expanding into vacuum," Plasma Phys. Control. Fusion 27(7), 717-749 (1985).

${ }^{\mathbf{2 4}}$ S. Creasey, D. Lewis, I. Smith, and W. Munz, "SEM image analysis of droplet formation during metal ion etching by a steered arc discharge," Surf. Coat. Technol. 97, 163-175 (1997).

${ }^{25}$ CRC Handbook of Chemistry and Physics, 92nd ed. (CRC Press, 2012), internet version. 